\title{
A educação democrática na escola deweyana: para discutir a relação entre educação escolar e democracia.
}

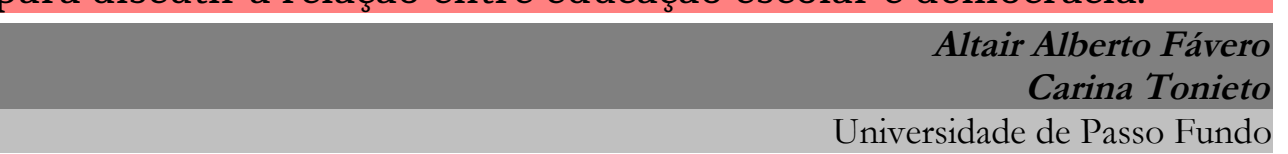

\section{Resumo}

O presente artigo tem como objetivo apresentar uma proposta de vivência da democracia na escola por meio da experiência democrática, ancorada na vivência de valores e práticas democráticas. Num primeiro momento localizaremos a discussão da relação entre educação escolar e democracia, a partir de Biesta (2013); num segundo momento apresentaremos a proposta de educação democrática de Dewey a partir da obra Democracia e educação (1959), com objetivo de mostrar qual a relação entre democracia e educação tendo como princípio pedagógico a reconstrução da experiência. Em seguida, apontaremos uma possibilidade de vivência da democracia na escola, por meio da experiência democrática, levando em consideração os escritos de Joseph Puig et al. na obra Democracia e participação escolar (2000), onde os autores pontuam quais são as características da escola democrática e como elas podem efetivar-se no cotidiano escolar.

Palavras-chave: Dewey, educação, democracia, escola.

\section{Abstract}

This paper aims to present a proposal to experience democracy in school through the democratic experience, anchored in the experience of democratic values and practices. At first, we will discuss the relationship between education and democracy, based on Biesta (2013). After that, we will present Dewey's democratic education proposal, focused on Democracy and Education (1959), in order to show the relationship between democracy and education, considering the reconstruction of experience as a pedagogical principle. Then, we will point out a possibility of living the democracy at school, through the democratic experience, considering Joseph Puig et al's book Democracy and participation in school (2000), work where the authors point out the characteristics of a democratic school and how they can become effective in the daily school routine.

Keywords: Dewey, education, democracy, school.

Filosofia e Educação [rfe] - volume 7, número 2 - Campinas, SP Junho-Setembro de 2015 - ISSN 1984-9605 - p. 


\section{Considerações iniciais}

o propor a discussão a respeito da educação democrática na
escola, surge de imediato a pergunta: Por que é importante
discutir a respeito da relação entre educação escolar e democracia? A primeira tentativa de resposta aponta para o fato de que a relação entre democracia e educação vem de longa data, isto é, desde a origem da democracia na polis ateniense, que se problematiza a respeito de que tipo de educação melhor prepararia o povo para a participação no governo da cidade (BIESTA, 2013, p.157). Apesar do longo tempo que separam os ideais democráticos da sociedade grega dos contemporâneos, ainda afirmamos que o papel da educação escolar é central para a democracia, ou seja, enquanto sociedades que ainda aspiram e lutam pela permanência e universalização dos ideais democráticos é necessário contar com a educação. O que mudou, no entanto, foi o objetivo da educação em relação à democracia. Se no passado ela era condição para a manutenção da vida democrática, hoje ela está mais fortemente vinculada à necessidade de se combater a apatia política (BIESTA, 2013, p.157). Desse modo, novos desafios se colocam às escolas, das quais se espera relevante contribuição para a formação de sujeitos capazes de compreender e transformar a sociedade, pautados em princípios éticos e políticos inerentes à vida democrática.

No entanto, a fim de buscar tais propósitos, optou-se muitas vezes por uma concepção instrumentalista de educação, onde o que se espera da escola é que prepare os futuros sujeitos democráticos para agir na sociedade democrática. Desse modo, devem prover as crianças e jovens de conhecimentos, habilidades e atitudes, que os tornem aptos para agir democraticamente no futuro. Para Biesta (2013, p.158) tal modo de compreensão acarretou na responsabilização das escolas pelo futuro da 
democracia, sendo "irrealista supor que as escolas podem criar ou romper a democracia”. Isso significa que, atribuir à escola a tarefa de educar para a democracia, é apostar numa proposta educativa que pouco contribui para a vivência da democracia como princípio pedagógico e político, pois à ela cabe apenas prover os futuros sujeitos de um gama de instrumentos para agir democraticamente no futuro. Desse modo, o que é importa é prover os cidadãos de conhecimentos, habilidades e das disposições democráticas, deixando de lado, por exemplo, a formulação de perguntas a respeito das relações humanas e destas com o contexto social e político onde se age e aprende (BIESTA, 2013, p.158). Assim, justifica-se a mera transmissão dos conhecimentos, treino para determinadas habilidades e exigência de determinadas atitudes, já que eles independem das relações com os demais e dos problemas da sociedade. Além disso, Biesta (2013, p.159) aponta que essa é uma "visão individualista da própria democracia", já que ela dependeria das inclinações dos próprios sujeitos para a ação democrática, assim como, de que todos agissem com essa condição. O problema desta compreensão reside na busca pela uniformização de modos de compreensão e ação, quando o que mais desafia a democracia, enquanto modo de vida, é a interação social pautada pelo respeito às diferenças e à multiplicidade, isto é, a convivência com aqueles que são, necessariamente, diferentes de nós e com a infinidade de possibilidades de modos de vida e de posicionamentos diante do contexto. Nesse sentido concordamos com Biesta que a vida democracia "consiste em pluralidade e diferença, e não na identidade e uniformidade" (2013, p.159).

Se a educação como preparação para a ação democrática no futuro não daria conta da formação democrática de crianças e jovens, qual seria a melhor maneira de a educação escolar contribuir para a formação de sujeitos democráticos? Seguindo a trilha de Biesta (2013), concordamos que 
somente preparar para o futuro, munindo crianças e jovens de conhecimentos e habilidades não é suficiente, assim como, que a responsabilidade de educar para a manutenção da democracia não é somente da escola, mas da sociedade como um todo. Porém, Biesta (2013, p.164) aponta que educar por meio da democracia, também não dá conta da educação democrática, por mais que se saiba que os estudantes aprendem muito mais quando participam ativamente das situações de aprendizagem, do que quando algo lhes é simplesmente ensinado. Tal apontamento sinaliza para o fato de que as escolas podem prever formalmente em suas propostas educativas a preocupação com a democracia, assim como, em seus currículos conteúdos e métodos para atingir tal objetivo, porém se ela não estiver organizada segundo os princípios democráticos, negará cotidianamente aquilo que busca ensinar. Na visão de Biesta (2013, p.165) educar por meio da democracia é um modo de educar para a democracia, ou seja, "um modo de afirmar que a melhor maneira de preparar para a democracia é por meio da participação na própria vida democrática”, tal observação serve tanto para a escola quanto para os demais espaços onde crianças e jovens aprendem.

No entanto, cabe destacar que a proposta de educar por meio da democracia, ao contrário do educar para a democracia, potencializa a preocupação com os outros e com a compreensão do contexto onde se aprende e se age. A vivência ou a experimentação dos princípios da vida democrática na escola potencializariam o desenvolvimento de modos de compreensão e ação democráticos. Desse modo, concordamos com Biesta (2013) que educar somente para a democracia futura, por meio da instrução, empobrece as possibilidades da educação democrática na escola, porém consideramos que educar implica em ter como horizonte o futuro. Quando o que se busca é somente prover os sujeitos de conhecimentos e habilidades

Filosofia e Educação [rfe] - volume 7, número 2 - Campinas, SP Junho-Setembro de 2015 - ISSN 1984-9605 - p. 75-93 
que lhes serão úteis no futuro, então concordamos que se empobrecem as possibilidades da educação democrática na escola, além disso, a sociedade cobrará a má preparação dos seus sujeitos. Por outro lado, discordamos dele em relação à educação por meio da experiência, pois consideramos que educar por meio da vivência de princípios democráticos na escola é um caminho promissor para a educação democrática, já que seria possível promover na escola espaços de experimentação dos princípios e valores democráticos que ajudariam na compreensão de que, viver democraticamente, significa conviver com as diferenças, com a multiplicidade de meios e opções de ação social. Nesse sentido, buscaremos abordar no presente texto a educação democrática na escola a partir da leitura de John Dewey (1959) e Joseph Puig et al. (2000), os quais, em nossa visão, oferecem bons elementos para projetarmos e agirmos em prol de uma educação democrática, os quais apontam que educar democraticamente é educar por meio da vivência de valores e princípios democráticos, cuja proposta consideramos promissora. Num primeiro momento localizaremos a proposta de educação democrática de Dewey a partir da obra Democracia e educação, a partir da qual mostraremos os pressupostos políticopedagógicos da relação entre democracia e educação. Em seguida, apontaremos com seria possível a experiência democrática na escola levando em consideração os escritos de Joseph Puig et al. na obra Democracia e participação escolar, onde os autores pontuam quais são as características da escola democrática. Busca-se, a partir desses três movimentos, oferecer uma resposta satisfatória, mesmo que provisória, para a pergunta, por que é importante discutir a respeito da relação entre educação escolar e democracia?

\section{A educação democrática segundo John Dewey}

Filosofia e Educação [rfe] - volume 7, número 2 - Campinas, SP Junho-Setembro de 2015 - ISSN 1984-9605 - p. 75-93 
A concepção de educação democrática de Dewey, parte da constatação de que educar é uma prática que existe em qualquer tipo de grupo social (1989, p.85). Porém, como há uma diversidade de grupos sociais, cada qual orienta o processo educativo das gerações mais novas, segundo os modos de vida estabelecidos do grupo e sua projeção de futuro. Isso implica em opções quanto ao modo de organização das escolas, o que será ensinado e como será ensinado. Assim, é notório que uma sociedade que "não somente muda, mas que, também, para estimulá-la, faz da mudança um ideal, terá normas e métodos educativos diferentes dos de outra que aspire meramente a perpetuação de seus próprios costumes" (DEWEY, 1959, p.86). Isso mostra que há diferenças entre as sociedades que mudam por mudar ou que esperam que a mudança aconteça por ela mesma, das sociedades que intencionalmente buscam a mudança para que o presente e futuro sejam melhores. Para essas sociedades em que a mudança, como forma de qualificação dos modos de vida predominam no grupo, a educação não é concebida como mera reprodução dos valores, hábitos e aspirações do grupo, mas como espaço de reconstrução deles com vista a um futuro melhor. É claro, nessa direção, que todo processo educativo inclui aspectos de socialização de seus membros de acordo com os modos de vida e valores do grupo, porém “a qualidade e o valor da socialização dependem dos hábitos e aspirações do grupo" (DEWEY, 1959, p.89), ou seja, se o que se busca é educar para a reprodução ou para a reconstrução.

Educar para a reprodução aponta para a perpetuação de determinadas práticas sociais e políticas que buscam passar à margem dos processos de transformação social, política, cultural e intelectual, sendo deste modo suficiente instrumentalizar as futuras gerações para agir no futuro, já que os futuros possíveis são dados de antemão. A reconstrução busca o movimento entre o passado, o presente e o futuro, de modo que por meio da valorização

Filosofia e Educação [rfe] - volume 7, número 2 - Campinas, SP Junho-Setembro de 2015 - ISSN 1984-9605 - p. 75-93 
das conquistas intelectuais, culturais, sociais e políticas da humanidade, busca-se compreender o presente com seus novos contornos e desafios, a fim de melhor aproveitar as mudanças para melhoria do presente e projeção do futuro, já que a mudança constante faz com que os traços do presente e do futuro assumam contornos não muito nítidos. Diante de tais constatações, isto é, que a projeção do processo educativo depende dos modos de vida do grupo e suas aspirações, faz-se necessário, para Dewey $(1959$, p.89) que se estabeleçam critérios para o julgamento dos diferentes modos de vida social, a fim de, identificar qual seria a melhor forma de educar. Para tal, ele adverte que precisamos evitar dois extremos: (i) o primeiro implica em não gastar energia na criação de uma sociedade ideal, pois se deve partir de sociedades reais a fim de garantir a execução do proposto, ou seja, o ideal não pode ser algo perfeito em si mesmo e, portanto, livre de todas as contradições e disputas inerentes a qualquer associação humana, pois, desse modo, seria irreal e tornaria inviável qualquer proposta de melhoria. (ii) $\mathrm{O}$ segundo extremo a ser evitado é que o ideal não pode reduzir-se a simples reprodução do que já existe, pois assim, também seria ineficiente qualquer proposta de melhoria, já que estaria trabalhando para a manutenção do que já está dado e deixando as mudanças ao cargo do acaso. Essas advertências de Dewey nos chamam a atenção para o fato de que propor uma educação democrática, não significa partir de uma sociedade e de uma escola perfeita em si mesma, nem pautar as ações na simples reprodução do que existe, mas projetar novos modos de vida levando em consideração as contingências e as contradições inerentes a qualquer forma de vida associada.

O esforço de analisar os modos de vida associada constatará que em qualquer tipo de organização social há "algum interesse comum" e "certa dose de interação e reciprocidade cooperativa com outros grupos" (DEWEY, 1959, p.89). A vida democrática seria, então, pautada por dois 
critérios: (i) o primeiro deles refere-se ao interesse comum, o que não significa somente aumento quantitativo dele, mas refere-se "a maior confiança no reconhecimento de serem, os interesses recíprocos, fatores de regulação ou direção social" (DEWEY, 1959, p.93), isto é, os interesses comuns são fonte de direção social e, portanto, reflexo de uma proposta de sociedade e não apenas representativos de interesses de alguns grupos; (ii) o segundo, diz respeito a interação e reciprocidade cooperativa, onde é importante o aumento da livre cooperação entre os grupos, mas o mais importante, é que este implique na "mudanças dos hábitos sociais - sua contínua readaptação para ajustar-se às novas situações criadas pelos vários intercâmbios" (DEWEY, 1959, p.93). No entanto, ambos devem levar em consideração o componente ético, ou seja, não são quaisquer interesses comuns, nem qualquer forma de interação que são salutares para o desenvolvimento individual e social, mas sim aqueles interesses que, ancorados em princípios éticos, podem ser partilhados e mutuamente comunicados. É levando em consideração tais elementos que Dewey propõe a democracia como forma de vida, para além de uma forma de governo. Em suas palavras: "uma democracia é mais que uma forma de governo; é, principalmente, uma forma de vida associada, de experiência conjunta e mutuamente comunicada" (1959, p.93), ou seja, a democracia enquanto forma de vida associada pressupõe interesses comuns, interação e reciprocidade cooperativa, amparada no diálogo e na participação ativa dos sujeitos envolvidos, tanto individualmente quanto coletivamente. Da mesma forma, ele aponta que a sociedade democrática deve preocupar-se com a formação de seus membros, uma vez que sendo uma sociedade que se adapta às mudanças e busca promovê-las é "uma sociedade móvel cheia de canais distribuidores de todas as mudanças ocorridas em qualquer parte" e por isso "deve tratar de fazer que seus membros sejam educados de modo a 
possuírem iniciativa individual e adaptabilidade", pois do contrário "serão esmagados pelas mudanças em que se virem envolvidos e cujas associações ou significações eles não percebem" (DEWEY, 1959, p.94). Desse modo, Dewey delineia os contornos que caracterizam um processo educativo democrático, afirmando a democracia como credo pedagógico (FÁVERO; TONIETO, 2011).

A possibilidade de educar democraticamente, para Dewey, está ligada à sua concepção de educação como reconstrução da experiência. Tal vinculação se dá devido ao fato de que a educação é sempre um fenômeno social e, enquanto tal, parte de uma concepção de sociedade, modo de vida e interação entre as pessoas. Assim, dependendo da concepção que se tem de sociedade e qual projeção de seu futuro pelas gerações mais velhas, organiza-se e dirige-se a educação das gerações mais novas. Para Dewey educação é "reconstrução ou reorganização da experiência" (1959, p.83), evidenciando que todo processo educativo não parte do vazio, mas de um conjunto de vivências, práticas e valores que cada sujeito constrói desde o seu nascimento e vai modelando durante toda a sua vida. Por isso, educar inclui ao mesmo tempo processo de esclarecimento, projeção e aumento da própria experiência pelo sujeito, já que ele, partindo de um conjunto de influências culturais, elabora e constrói modos de compreensão daquilo que lhe acontece enquanto indivíduo e membro de uma comunidade. É nesse espaço de reelaborações constantes que as propostas educativas ganham significado e são potencializadas como propostas de construção de novos modos de compreensão e ação. Por isso, podemos afirmar, na trilha de Dewey, de que a função do ato educativo é "poder provocar intencionalmente consequências em vez de limitar-se a esperá-la surgir" (1959, p.83), ou seja, educar não é esperar que as coisas aconteçam espontaneamente e, nem somente preparar para o futuro, mas investir em

Filosofia e Educação [rfe] - volume 7, número 2 - Campinas, SP Junho-Setembro de 2015 - ISSN 1984-9605 - p. 75-93 
práticas educativas capazes de reconstruir o modo como se compreende e se age, não pela contemplação, mas pela experimentação, pela prática constante de hábitos de pensamento e de ação salutares, já que o que se busca é o desenvolvimento do sujeito em seus aspectos físicos, intelectuais e morais (DEWEY, 1979, p. 27). Tal proposta é reveladora de que não são quaisquer hábitos de pensamento e de ação que são desejáveis, mas aqueles que contribuem para o desenvolvimento dos sujeitos intelectualmente, moralmente e politicamente, evidenciando desse modo que o componente ético é uma constante do processo educativo, ou seja, ele define o fim a que tendem todas as ações educativas (DEWEY, 1979, p.26-27).

Projetar modos de compreensão e de ação salutares que levem em consideração o passado, para a construção do presente e projeção do futuro é um dos desafios que se coloca para o processo educativo, por isso as atividades escolares, as matérias de estudo e as práticas educativas não possuem um fim em si mesma, mas naquilo que podem proporcionar enquanto espaço de reconstrução de experiências de pensamento e de ação, tanto individuais quanto sociais. Tal movimento, na visão de Dewey, caracteriza o princípio da continuidade da experiência ou continnum experencial que "significa que toda e qualquer experiência toma algo das experiências passadas e modifica de algum modo as experiências subsequentes" (1979, p.26), constituindo-se como critério para o julgamento do valor ético-pedagógico de uma experiência educativa. Nessa direção, Dewey $(1959$, p.86) afirma que compreender a educação como contínua reconstrução da experiência é contrapor-se a "educação como preparação para um futuro remoto, como desdobramento, como formação externa e como repetição do passado" já que: (i) é compreensão e ação presente, ou seja, vive-se, compreende-se e age-se no tempo presente e não em outro, constrói-se significado e sentido na experiência presente e isso implica em 
discutir o presente à luz do passado, tendo como horizonte o futuro. Por isso a proposta de educação como simples preparação para o futuro não existe, o que existe são possíveis consequências (DEWEY, 1979, p. 43-44); (ii) é constante movimento, tanto de pensamento quanto de ação e, nesse sentido, é tanto aprendizagem de conteúdo quando de método. A proposta de educação democrática proposta por Joseph Puig e colaboradores, que apresentaremos a seguir, aponta uma possibilidade de vivência dos valores e práticas democráticas na escola por meio da participação escolar experimentada no presente, configurando-se como um dos caminhos salutares para o enriquecimento da relação da escola e seus sujeitos com a proposta de educação democrática.

\section{A vivência da democracia na escola}

Até o momento procuramos pontuar a partir da concepção democrática de educação de Dewey, quais seriam os contornos de uma proposta educativa escolar ancorada em princípios democráticos. Um deles está ligado a uma proposta pedagógica que tenha como princípio educativo a reconstrução da experiência e como fim promover o desenvolvimento físico, intelectual, moral e político, tanto individualmente quanto coletivamente; o outro princípio democrático está ligado a um projeto de sociedade que considera o presente e o futuro. Poderíamos afirmar, desse modo, que educar democraticamente é educar moralmente, intelectualmente e politicamente para a ação no presente e não somente no futuro. Nessa direção Joseph Puig et al. (2000, p.22) afirmam que as instituições que caracterizam uma sociedade democrática deveriam ter suas ações pautadas por critérios de igualdade, liberdade, participação e justiça. No caso da escola, isto se torna ainda mais evidente e necessário, já que ela é uma das instituições responsáveis por ensinar "o que significa viver democraticamente e isso 
somente se alcança vivendo democraticamente" (Puig et al., 2000, p.22). No entanto, há de considerar-se que a escola não consegue, e nem deveria ser esse seu objetivo, reproduzir fielmente a vida social, porém ela pode promover em seu cotidiano experiências educativas democráticas, onde se vivencia a igualdade, a participação e a justiça, o que Dewey denomina de “arranjo social global onde a pessoa está inserida" (1979, p. 38)

A escola, como toda instituição pautada em critérios de vida associada e mutuamente comunicada, é constituída por sujeitos que possuem conjuntos de interesses comuns e diversos, porém eles não ocupam a mesma posição quanto aos modos de compreensão, conhecimento e experiência, o que não impede a ação cooperativa. Para Puig et al. (2000, p.26) uma instituição pode ser qualificada de democrática quando consegue "um bom equilíbrio no jogo da assimetria funcional e da simetria democrática". Isso significa que na escola, assim como na vida, os sujeitos possuem diferenças quanto aos modos de compreensão, regulação e funções que desempenham, mas que isso não elimina os seus interesses comuns e a condição de membros de uma sociedade democrática. É nesse sentido que as práticas escolas poderão ser pautadas pela interação e reciprocidade cooperativa, possíveis por meio da vivência da igualdade, participação e justiça, que são princípios éticos reguladores da vida em conjunto. Assim, pode-se afirmar que a escola educa democraticamente, quando promove espaços de participação, diálogo e tomada de decisão, naqueles assuntos em que é possível equilibrar as assimetrias individuais em favor da simetria democrática.

Nessa direção Puig et al. (2000, p.27-28) salientam que a escola democrática almeja oportunizar aos seus alunos a experiência de viver em uma sociedade democrática, por meio da vivência de práticas e valores democráticos, o que inclui a participação efetiva em todos os aspectos do

Filosofia e Educação [rfe] - volume 7, número 2 - Campinas, SP Junho-Setembro de 2015 - ISSN 1984-9605 - p. 75-93 
processo formativo em que é cabível a sua inserção, o que implica em não limitar em excesso e nem atribuir responsabilidades e tarefas que não thes cabem. Nesse sentido, fica evidente a proposta de que educar democraticamente significa reconhecer os limites da ação estudantil, ou seja, reconhecer regras e respeitá-las coletivamente faz parte da aprendizagem coletiva, assim como, de propor discussões salutares a respeito delas, apontando para a possibilidade de discussão crítica e coletiva. $\mathrm{O}$ equilíbrio, nesse jogo, é alcançado quando alunos e professores possuem responsabilidades complementares, de acordo com seus papéis e circunstâncias; quando a escola privilegia a participação como forma de construção da autonomia e da responsabilidade, apostando na sua amplitude enquanto reconstrução da experiência individual e social que pode ser estendida para fora dos espaços escolares. As relações democráticas, no entanto, não são estabelecidas do nada, mas segundo balizadores que orientam e permitem avaliar o "clima escolar democrático", que são, na visão de Puig et al. (2000, p.29), os valores e as práticas escolares. Os valores indicariam e recolocariam permanentemente quais são os objetivos e finalidades da escola, nutrindo de significado as práticas educativas concretas; as práticas por sua vez promoveriam no cotidiano escolar a vivência dos valores pretendidos, recorrendo para isso ao uso de procedimentos e estratégias, não vazios e com fins neles mesmos, mas perpassados por conteúdos de aprendizagem. Para eles "pensar uma escola democrática significa estabelecer valores que devem guiar os métodos que farão possível a sua concretização em cada instituição" (Puig et al., 2000, p.29).

$\mathrm{Na}$ falta de valores e fins que orientem o funcionamento da escola democrática, as melhores propostas curriculares falham, pois não tem sentido, não tem uma razão de ser. Os valores dinamizam a ação educativa,

Filosofia e Educação [rfe] - volume 7, número 2 - Campinas, SP Junho-Setembro de 2015 - ISSN 1984-9605 - p. 75-93 
pois tem o apreço da comunidade escolar e estão em consonância com aquilo que é esperado da escola. Entretanto, é preciso evitar um equívoco: os valores não servem para detalhar as práticas pedagógicas, mas para sinalizar a direção que devem seguir, assim como, balizadores que ajudam na identificação de erros e correção de rota. Mas quais seriam esses valores? A escola democrática deve levar em consideração os valores que orientam a vida democrática, tais como, igualdade, liberdade, reciprocidade, autonomia, espírito crítico, responsabilidade, iniciativa, cooperação, solidariedade, tolerância, diálogo, autorregulação e adaptabilidade. Tal conjunto de valores, defendidos por Puig et. al., funcionam como balizadores da escola democrática, reafirmando a convicção de Dewey, de que sem valores éticos não há vida democrática e sim apenas laços de cooperação baseados em interesses particulares, desvinculados de qualquer preocupação social.

Por outro lado, a escola democrática, assim como a vida democrática, necessita de práticas que tornem possível a vivência desses ideais concretamente. Isso significa que a escola precisa promover em suas práticas a experimentação dos valores democráticos. Trata-se, então, de ver que práticas são esperadas de uma escola democrática. Em primeiro lugar são práticas que impulsionam a participação, ou seja, "práticas de participação que tornam possível aos alunos e às alunas tomar parte ativa e significativa na vida da escola, quer dizer, nas questões relativas ao trabalho escolar, à convivência e à integração" (Puig et. al., 2000, p.31). É nessa dimensão que visualizamos a proposta de Dewey de reconstrução da experiência e de educação democrática, já que ao tomar parte ativa em grupos de indivíduos que possuem interesses comuns e que, por isso, discutem e tomam decisões levando em consideração o bem-estar coletivo, evidencia-se que tanto os interesses coletivos quanto a interação estão 
ancorados em princípios éticos, o que caracteriza uma vida democrática. Além disso, essas práticas são práticas educativas orientadas, ou seja, não dispensam ou minimizam a ação dos professores, mas ressaltam a sua importância, a fim de ampliar a eficácia formativa dos processos que se desenrolam, os quais são promotores do desenvolvimento individual e coletivo, intelectual e moral (TONIETO, 2010). Por isso, novamente afirmamos, que não se trata de preparação para vida democrática futura, mas de vivência da democracia no cotidiano escolar como forma de reconstrução da experiência e por isso de ampliação dos repertórios de ação, provocadores de novos modos de compreensão e intervenção na vida social mais ampla.

A função da escola que se propõe a educar democraticamente, não cabe simples transferências ou adaptações da vida social, mas organizar seu trabalho de modo que torne evidentes e experienciáveis os princípios de uma vida democrática. Isto significa que os alunos, pelas experiências democráticas nas quais estão envolvidos, aprendem a enfrentar problemas que fazem parte da vida social de maneira justa e solidária amparados por critérios sociomorais, ao invés de modos mecânicos de enfrentamento. Trata-se, então, de ver que práticas são esperadas de uma escola democrática. Em primeiro lugar são práticas que impulsionam a participação, pois o objetivo é promover espaços de atividade sociomoral. Essas práticas, no entanto, não dispensam ou minimizam a ação do professor, mas precisam de sua ajuda intensa, pois se trata de "práticas de participação guiada" (Puig et. al., 2000, p.32), onde os processos pedagógicos demandam a intervenção dos educadores a fim de ampliar a eficácia formativa dos processos de aprendizagem.

Educar democraticamente, na perspectiva de Dewey e Puig et. al., está para além da instrução e de preparação para o futuro, o que não 
significa que ambas devem ser desconsideradas, mas sim que elas precisam estar acompanhadas de experiências educativas que oportunizem o desenvolvimento social e individual presente levando sempre em consideração os outros e o contexto. Desse modo, seria possível experimentar e enfrentar as dificuldades e facilidades da vida democrática no ambiente escolar, como forma de compreender as implicações da vida em grupo. É na constituição desses espaços escolares de formação individual e social, que vislumbramos uma das possibilidades de construção de "uma forma de vida associada, de experiência conjunta e mutuamente comunicada", ou seja, da democracia como forma de vida (DEWEY, 1959, p.93). Os objetivos educacionais a partir de tal proposta, não estão postos naquilo que se espera dos estudantes no futuro, mas daquilo que se espera deles no presente, ou seja, que se desenvolvam enquanto parte de um grupo, pela vivência de determinadas práticas e valores, que serão constantemente reconstruídas pela interação constante com outros grupos e novas possibilidades de ação social. Assim a escola não se limita a instrumentalizar, mas promover espaços de aprendizagem social e moral que permite aos sujeitos inscrever-se em outras lógicas de compreensão da dinâmica social da vida em grupo, sendo uma delas a da vida democrática.

\section{Considerações finais}

Educar democraticamente é um princípio, que tem dentre seus objetivos, contribuir para a formação de sujeitos capazes de compreender e transformar o contexto onde vivem. Para compreender e transformar é necessário desenvolver-se intelectualmente, moralmente, culturalmente, socialmente e politicamente. Apesar de não ser exclusivamente a escola responsável por tais dimensões, mas toda a sociedade, pois é sabido que há muitas aprendizagens que são feitas fora dela, ela desempenha um papel

Filosofia e Educação [rfe] - volume 7, número 2 - Campinas, SP Junho-Setembro de 2015 - ISSN 1984-9605 - p. 75-93 
fundamental na consecução dos ideais democráticos. Nesse sentido concordamos com Nussbaum que "o que oferecem as escolas mediante os conteúdos que ensinam e os métodos pedagógicos que aplicam podem afetar em grande medida a mente das crianças em desenvolvimento" (2010, p.73tradução livre), o que significa que a escolarização permite aos indivíduos inscrever-se numa nova lógica de compreensão de si mesmo, do mundo e dos outros, sendo uma delas a perspectiva de compreender e agir segundo princípios e valores democráticos. Inscrever-se nessa lógica seria o espaço de reconstrução da experiência democrática na escola.

Dewey (1959, p.93) lembra-nos que a democracia como "forma de vida associada, de experiência conjunta e mutuamente comunicada", pressupõe interesses comuns, interação e reciprocidade cooperativa, amparada no diálogo e na participação ativa e, desse modo, deve almejar por um processo educativo que impulsione a constante reconstrução de saberes e práticas sociais. Puig et. al. (2000), por sua vez, mostram-nos como é possível a vivência de determinados princípios e valores democráticos por meio da participação escolar, apontando que a escola democrática oportuniza a experiência, mesmo que parcial e contingente, de viver em uma sociedade democrática, os quais são perceptíveis e observáveis nas ações escolares cotidianas. Nessa direção consideramos, também, o desafio que se recoloca permanentemente para a educação diante do contexto de sociedades plurais e complexas, onde a democracia não é mais uma questão local, mas global; onde se esfacelaram os ideais conservadores de educação, mostrando as múltiplas possibilidades de aprendizagem e de relação com o mundo, com os outros, consigo mesmo e com o conhecimento; onde a comunicação instantânea e global nos desafia permanentemente com o seu potencial criador e de mobilização em escalas nunca dantes imaginadas. Porém, ligados a todos esses movimentos em escala global, continuamos 
aspirando por valores e práticas sociais e democráticas, pois eles continuam figurando como balizadores de uma sociedade justa. Assim, os valores e práticas democráticas são reconhecidamente os qualificadores da ação e, por isso, independentemente dos movimentos de transformação da vida social, continuam sendo temas centrais para a educação.

A educação escolar democrática, vista como experiência democrática, é um agente que contribui significativamente para os debates e embates democráticos, apontando limites, possibilidades e desafiando a ação, mas principalmente um espaço de construção de referenciais democráticos pela ação presente no cotidiano escolar e não como expectativa de que no futuro, os sujeitos bem-dotados de conhecimentos e habilidades, assim ajam. Assim, se evitaria tanto o ativismo pedagógico vazio, quanto a inércia pedagógica justificada pela preparação para o futuro.

\section{Referências}

BIESTA, Gert. Para além da aprendizagem: educação democrática para um futuro humano. São Paulo: Autêntica, 2013.

DEWEY, John. Democracia e educação: introdução à filosofia da educação. São Paulo: Companhia Editora Nacional, 1959. . Experiência e educação. São Paulo: Ed. Nacional, 1979.

FÁVERO, Altair A; TONIETO, Carina. A democracia como credo pedagógico na filosofia de John Dewey. In: (org.). Leituras sobre John Dewey e a educação. Campinas/SP: Mercado de Letras, 2011, p.103128.

NUSSBAUM, Martha C. Sin fines de lucro: por qué la democracia necessita de las humanidades. Buenos Aires: Katz, 2010.

PUIG, Josep M.; MAERTÍN, Xus; ESCARBÍDUL, Susagna; NOVELLA, Anna M. Democracia e participação escolar. São Paulo: Moderna, 2000. 
TONIETO, Carina. Educação para o pensar como política educacional para a educação básica. 2010. Dissertação (Mestrado em Educação) Programa de Pós-graduação em Educação, Universidade de Passo Fundo, Passo Fundo, 2010. 